\title{
Neurotensin and Bombesin, a Relationship Between their Effects on Body Temperature and Locomotor Activity?
}

\author{
TJ. B. VAN WIMERSMA GREIDANUS, J. A. SCHIJFF, J. L. NOTEBOOM, \\ M. C. SPIT, L. BRUINS, M. VAN ZUMMEREN AND G. J. E. RINKEL \\ Rudolf Magnus Institute for Pharmacology, Medical Faculty, University of Utrecht \\ Vondellaan 6, 3521 GD Utrecht, The Netherlands
}

Received 8 July 1983

\begin{abstract}
VAN WIMERSMA GREIDANUS, TJ. B., J. A. SCHIJFF, J. L. NOTEBOOM, M. C. SPIT, L. BRUINS, M. VAN ZUMMEREN AND G. J. E. RINKEL. Neurotensin and bombesin, a relationship between their effects on body temperature and locomotor activity? PHARMACOL BIOCHEM BEHAV 21(2) 197-202, 1984.- Neurotensin and bombesin have been tested for their effects on body temperature and locomotor activity in an open field. Both peptides induce hypothermia and suppress ambulation and rearing. The time curves of the hypothermic effects of both peptides appear to be rather similar, although bombesin is a more potent hypothermic agent than neurotensin. The time curves of the effects on locomotor activity appear to be quite different. The suppressive effect of neurotensin on locomotor activity is relatively short lasting and reaches its maximum at approximately 32 minutes. The effect of bombesin follows a different time curve and shows two peaks, suggesting that two different mechanisms are involved in the suppressive action of bombesin on locomotor activity. Calculation of the correlation coefficients between the effects of neurotensin and of bombesin on body temperature and on locomotor activity (ambulation) suggest that a causal relationship between these two effects is not likely, in particular for neurotensin.
\end{abstract}

Neurotensin Bombesin Body temperature Locomotor activity

NEUROTENSIN is a tridecapeptide found in the gut and in several regions of the brain. It produces various effects after central, mostly intracerebroventricular (ICV) administration. These effects include hypothermia [2], diminished locomotor activity, muscle relaxation [16], catalepsy [20] and antinociception [7]. It has been suggested originally that the behavioral effects exerted by centrally administered neurotensin might be explained by the potent hypothermic action [3]. However, Martin, Naruse and Papp [14] provided evidence that the antinociceptive effect of neurotensin, as measured in a hot plate situation, and the effect of the peptide on body temperature are two distinct responses. In addition, catalepsy induced by ICV injection of neurotensin has been demonstrated not to be correlated with the hypothermia induced by the peptide [20]. In addition, a dichotomous action between neurotensin and structural analogues on motor activity in rats was found, whereas such a dichotomy was not observed for the hypothermic and muscular relaxation effects of neurotensin [10]. Finally, a dissociation between the hypothermic and antinociceptive effects of neurotensin has been achieved by bilateral microinjection of neurotensin into a large number of separate loci in the rat brain [11]. Thus, neither the neurotensin-induced catalepsy nor the antinociception nor the decreased motor activity seem to be consequences of the hypothermia.

Bombesin is a tetradecapeptide, which is found, as neurotensin, in gut and brain [6]. Upon central administra- tion it has some effects in common with neurotensin such as hypothermia [1, 4, 5] and antinociception [18]. In addition it reduces food intake [8] and feeding behavior [13], it induces excessive grooming $[9,12]$ and affects locomotor activity [18]. Thus neurotensin and bombesin, although of different structure share several properties (see for review [17]).

The present study was designed to assess whether neurotensin and bombesin have comparable effects on locomotor activity and on body temperature and whether a causal relationship exists between the hypothermic actions of these peptides and their effects on locomotor activity.

\section{METHOD}

Male rats of an inbred Wistar strain (TNO, Zeist, The Netherlands), weighing 140-160 g were used. Prior to experimentation animals were operated under Hypnorm ${ }^{\circledR}(5.0 \mathrm{mg}$ fluanison and $0.2 \mathrm{mg}$ fentanyl $/ 0.5 \mathrm{ml} / \mathrm{kg}, \mathrm{SC}$; Duphar B.V., Amsterdam, The Netherlands) anesthesia for cannulation of the brain ventricular system. A polyethylene cannula was placed into the right ventricle of the rat brain and anchored with 1 stainless steel screw and dental cement. During recovery from the operation, which usually took 3-4 days, animals were daily handled. They were individually housed and kept at a room temperature of $22^{\circ} \mathrm{C}$. After recovery from operation animals were subjected to experimentation. At the end of each experiment an ICV injection of Evans Blue was 
TABLE 1

EFFECT OF $3 \mu \mathrm{g}$ NEUROTENSIN (ICV) ON BODY TEMPERATURE AND ON OPEN FIELD ACTIVITY AT VARIOUS TIME INTERVALS

\begin{tabular}{lcccc}
\hline & & $\begin{array}{c}\text { Mean body } \\
\text { temperature } \\
( \pm \mathrm{SEM}){ }^{\circ} \mathrm{C}\end{array}$ & $\begin{array}{c}\text { Mean ambulation }( \pm \mathrm{SEM}) \\
\text { (crossings in open } \\
\text { field } / 3 \mathrm{~min})\end{array}$ & $\begin{array}{c}\text { Mean } \\
\text { rearing } \\
\text { frequency } \\
( \pm \mathrm{SEM}) / 3 \mathrm{~min}\end{array}$ \\
\hline Placebo & $(8)$ & $37.5 \pm 0.1$ & $71.9 \pm 6.8$ & $7.6 \pm 1.1$ \\
$20^{\prime}$ & $(8)$ & $37.2 \pm 0.2^{*}$ & $57.0 \pm 5.5$ & $5.6 \pm 1.0$ \\
$40^{\prime}$ & $(8)$ & $36.4 \pm 0.3^{\dagger}$ & $53.0 \pm 5.0^{*}$ & $6.1 \pm 0.8$ \\
$60^{\prime}$ & $(12)$ & $36.6 \pm 0.34^{\dagger}$ & $62.6 \pm 7.0$ & $6.7 \pm 0.9$ \\
$80^{\prime}$ & $(7)$ & $37.0 \pm 0.3$ & $78.3 \pm 1.9$ & $6.4 \pm 0.9$ \\
\hline
\end{tabular}

( ) Number of animals/group.

${ }^{*} p<0.05$ (vs. placebo, Dunnet's test).

$\dagger p<0.01$ (vs. placebo, Dunnet's test).

given and the staining of the ventricular system of the brain was inspected to establish the placement of the cannula. Only data from animals with a correct position of the tip of the cannula were used for evaluation of the results.

Body (rectal) temperature was registered using a telethermometer (Yellow Springs Instrument Co. Inc., USA). The thermometer was inserted $4 \mathrm{~cm}$ into the rectum for 15 sec. Ambient temperature in the experimental room was $22 \pm 1^{\circ} \mathrm{C}$.

Locomotor activity was studied in a circular open field [21] with a diameter of $75 \mathrm{~cm}$. A 40 Watt bulb was placed 40 $\mathrm{cm}$ above the floor of the open field. During 3 min sessions the following parameters were measured: ambulation (number of crossings of lines drawn on the floor of the open field), frequency of rearing and grooming, and defecation (number of boluses).

In initial experiments we calculated the mean $( \pm S E M)$ scores of ambulation, rearing, grooming and defecation, as well as the mean $( \pm S E M)$ body temperature in different groups of animals at various timepoints after treatment with placebo or peptide.

\section{Neurotensin Experiments}

Neurotensin (R 4322, Bachem, Torrance, CA) was ICV administered in a dose of $3 \mu \mathrm{g}$, dissolved in an injection volume of $2 \mu \mathrm{l}$ artificial CSF, which was used as placebo. In a first series of experiments rectal temperature was registered at 20, 40,60 and 80 min after injection of neurotensin, and compared with pre-injection (control) temperature. In a second series of experiments animals were ICV injected with either $3 \mu \mathrm{g}$ neurotensin or placebo and at similar timepoints as used in the first series of experiments, placed in the open field for observation of locomotor activity. In a third series of experiments animals were injected with either neurotensin ( $3 \mu \mathrm{g}, \mathrm{ICV}$ ) or placebo and tested for rectal temperature at the mentioned timepoints. Immediately after measuring this temperature, the animals were placed in the open field for observation of locomotor activity.

For assessment of a time-effect relationship curve of the effect of neurotensin on body temperature and on locomotor activity we used (1) the difference between the mean ambulation score of each neurotensin treated group of animals at the mentioned timepoints and the mean ambulation score of the control group ( $\Delta$ amb.) and (2) the mean difference in rectal temperature of each group of animals before and 20 , 40,60 or $80 \mathrm{~min}$ after neurotensin administration ( $\Delta$ temp.). Thus for the measurement of the hypothermic effect of neurotensin each animal was its own control, whereas in the behavioral experiments the locomotor activity of each neurotensin treated animal was compared with the mean locomotor activity of a placebo treated control group.

This procedure was chosen in order to avoid the diminished exploratory behavior or reduction of locomotor activity, which occurs at repeated testing of locomotor activity of rats in an open field. Repeated measurement of rectal temperature does not affect this temperature as such.

In this way the mean $\Delta$ amb. and the mean $\Delta$ temp. were calculated at the various timepoints.

In addition a dose response study on the hypothermic effect of neurotensin and on its suppressive action on locomotor activity was performed at one timepoint $(30 \mathrm{~min})$.

\section{Bombesin Experiments}

Bombesin (batch 42-218-25) (Bombesin was obtained from Dr. J. Rivier, the Salk Institute, La Jolla, CA) was ICV administered in a dose of $300 \mathrm{ng} / 2 \mu \mathrm{l}$ artificial CSF. During the first experiments similar timepoints as used for neurotensin were applied (i.e., 20, 40, 60 and $80 \mathrm{~min}$ ) for testing the effect of bombesin on rectal temperature and on open field behavior. Since the data from these initial experiments did not result in a clear-cut time curve for the effect of bombesin on locomotor activity in the open field, other timepoints were included as well and additional experiments were performed using a $10,20,30,40,50,60,80$ and $100 \mathrm{~min}$ time interval.

Calculation of the mean $\Delta \mathrm{amb}$. and the mean $\Delta$ temp. as result of the bombesin treatment at the various timepoints, as well as assessment of a correlation between the effect of bombesin on body temperature and on locomotor activity was performed in a similar way as applied for neurotensin. In addition a dose response study was performed on the hypothermic effect of bombesin at $45 \mathrm{~min}$ and on its suppressive effect on ambulation at $30 \mathrm{~min}$.

Statistical evaluation of the various data on the timeeffect relationship studies was performed by using analysis of variance (ANOVA) or Dunnett's test as appropriate. Cor- 
relation coefficients were calculated using Spearman's rank correlation test [19]. The table used for the critical values of the Spearman rank correlation coefficient is a one-tailed table (see [19]).

\section{RESULTS}

\section{Neurotensin}

ICV administration of $3 \mu \mathrm{g}$ neurotensin induces a significant fall in body temperature starting at $20 \mathrm{~min}$ after injection and continuing for over $1 \mathrm{hr}$ (Table 1). Since from the timepoints used the lowest temperature was registered at 40 min and the second lowest at $60 \mathrm{~min}$, the maximum effect can be expected to occur between 40 and $60 \mathrm{~min}$. For the effect of neurotensin on ambulation the strongest effect was seen at $40 \mathrm{~min}, 20 \mathrm{~min}$ being second and $60 \mathrm{~min}$ third (Table 1), indicating that the maximum effect will occur between 20 min and $40 \mathrm{~min}$. For the influence of neurotensin on rearing the maximum seems also to occur between $20 \mathrm{~min}$ and 40 min, although no significant effect was observed (Table 1). Grooming and defecation were not significantly affected by neurotensin (data not shown).

Using the calculated mean $\Delta$ temp. and mean $\Delta \mathrm{amb}$. from the various experiments a time-effect relationship curve was constructed which reveals that neurotensin $(3.0 \mu \mathrm{g}$ ICV) exerts its maximal effect on rectal temperature at $43 \mathrm{~min}(\Delta$ temp. max) and its maximal effect on ambulation at $32 \mathrm{~min}(\Delta$ amb. max) (Fig. 1).

In addition, of all neurotensin treated rats listed for rectal temperature and locomotor activity at 20,30, 40,60 and 80 min (53 animals, see Tables 2 and 3) 8 animals showed a significant fall in body temperature without displaying a reduction in ambulation. Conversely, of 14 rats which did not show a neurotensin-induced hypothermia 9 animals showed a reduced ambulation.

Results of the dose-response relationship study reveal that the various doses of neurotensin all result in a similar fall in body temperature, whereas the effect of $1 \mu \mathrm{g}$ neurotensin on ambulation is much less pronounced than that observed after administration of higher doses of the peptide (data not shown).

Calculation of the correlation coefficient between hypothermia and reduction of ambulation at the various timepoints used revealed that generally no correlation exists between these two parameters (Table 2). Only at $40 \mathrm{~min}$ a weak but significant correlation exists between $\Delta$ amb. and $\Delta$ temp. A more or less similar result is found calculating this correlation coefficient in the dose-response experiment (Table 3). Only the highest dose of neurotensin results in a weak but significant correlation between the hypothermic effect and the suppressive action on locomotion.

\section{Bombesin}

ICV administration of $300 \mathrm{ng}$ bombesin induces a significant fall in body temperature starting at 20 min after injection and lasting approximately $1 \mathrm{hr}$. From the timepoints used the 50 min time interval showed the largest effect, whereas at $\mathbf{4 0}$ min the second lowest temperature was registered (Table 4). Thus, the maximum effect of $300 \mathrm{ng}$ bombesin on body temperature can be expected to occur between 40 and $50 \mathrm{~min}$.

Bombesin reduces locomotor activity (ambulation and rearing) in the open field. For the effect on ambulation the strongest effects were seen at two timepoints: $30 \mathrm{~min}$ and 60 min with a markedly weaker effect in between at $40 \mathrm{~min}$. A

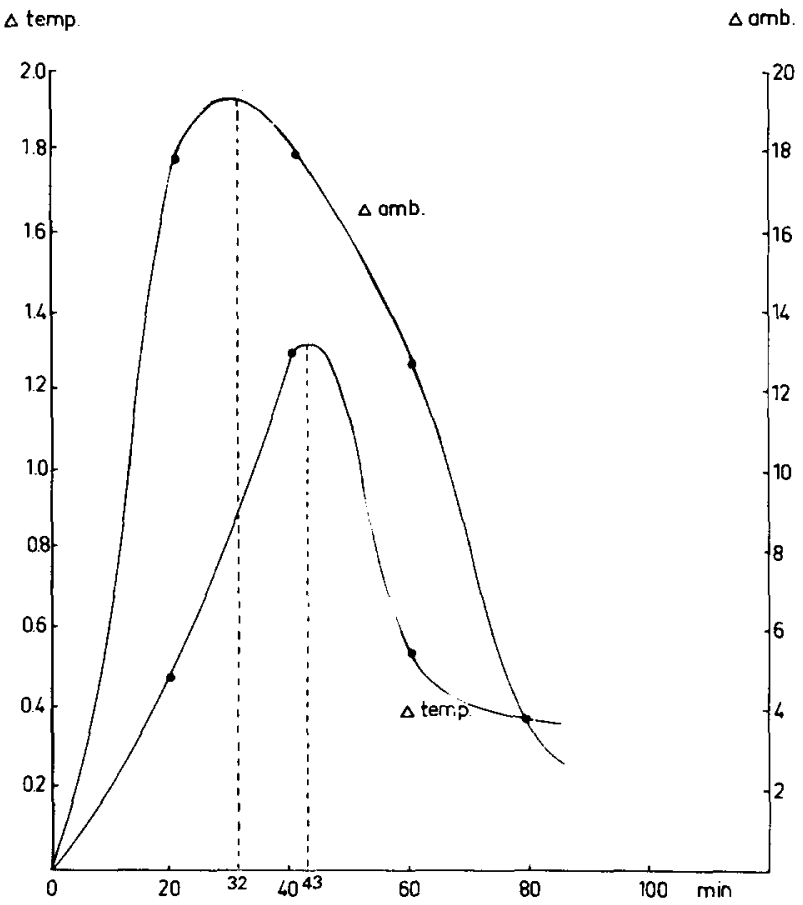

FIG. 1. Time curves of the effect of neurotensin ( $3 \mu \mathrm{g}$, ICV) on body temperature ( $\Delta$ temp.) and on ambulation $(\Delta a m b$.$) in an open field.$

more or less comparable effect of bombesin was observed on rearing frequency (Table 4). Grooming as observed in the open field was not significantly affected by bombesin, although during the first $30 \mathrm{~min}$ after injection a tendency towards more grooming and increased scratching was observed. Generally defecation was slightly reduced after administration of bombesin (data not shown).

Using the calculated $\Delta$ temp. and $\Delta$ amb. from the various experiments a time-effect relationship curve was constructed which reveals that bombesin ( $300 \mathrm{ng} \mathrm{ICV})$ exerts its maximal hypothermic effect at $47 \mathrm{~min}$ (Fig. 2). For the effect of bombesin on ambulation a biphasic curve appears with a sharp peak at $28 \mathrm{~min}$ and a second maximum at approximately $65 \mathrm{~min}$ (Fig. 2). It also appears that the suppressive effect of bombesin on locomotor activity is long lasting $(>100 \mathrm{~min})$.

Of all bombesin treated rats listed for rectal temperature and locomotor activity (42 animals, see Tables 5 and 6), 6 animals showed a bombesin-induced reduction of ambulation without a significant fall in body temperature. Conversely, of 35 animals which were hypothermic following bombesin treatment 7 animals did not show a reduction of ambulation.

Calculation of the correlation coefficient between the hypothermic effect of bombesin and the bombesin-induced reduction of ambulation at the various timepoints used revealed that a weak but significant $(p=0.05)$ correlation exists between these two parameters (Table 5). However, a negative result was found in the dose-response experiment (Table 6). In addition the low dose of bombesin $(30 \mathrm{ng})$ does not reduce ambulation and rearing, but does induce hypothermia (data not shown).

\section{DISCUSSION}

The present data clearly confirm previous findings $[2,13$, 
TABLE 2

CORRELATION COEFFICIENT FOR $\triangle$ AMBULATION AND $\Delta$ TEMPERATURE AT VARIOUS TIME INTERVALS AFTER ICV ADMINISTRATION OF $3 \mu \mathrm{g}$ NEUROTENSIN

\begin{tabular}{ccc}
\hline $\begin{array}{c}\text { Time interval } \\
\text { (min) }\end{array}$ & $\begin{array}{c}\text { Number } \\
\text { of rats }\end{array}$ & $\begin{array}{c}\text { Spearman rank } \\
\text { correlation } \\
\text { coefficient }\end{array}$ \\
\hline 20 & 10 & 0.176 \\
40 & 8 & $0.798^{*}$ \\
60 & 10 & 0.448 \\
80 & 7 & -0.286 \\
\hline
\end{tabular}

TABLE 3

CORRELATION COEFFICIENT FOR $\triangle$ AMBULATION AND $\triangle$ TEMPERATURE AT 30 MIN AFTER ICV ADMINISTRATION OF GRADED DOSES OF NEUROTENSIN

\begin{tabular}{ccc}
$\begin{array}{c}\text { Doses neurotensin } \\
(\mu \mathrm{g}, \mathrm{ICV})\end{array}$ & $\begin{array}{c}\text { Number } \\
\text { of rats }\end{array}$ & $\begin{array}{c}\text { Spearman rank } \\
\text { correlation } \\
\text { coefficient }\end{array}$ \\
\hline 1 & 6 & 0.171 \\
3 & 5 & 0.600 \\
10 & 7 & $0.714^{*}$ \\
\hline
\end{tabular}

$p=0.05$ (one-tailed test).

${ }^{*} p<0.05$ (one-tailed test).

TABLE 4

EFFECT OF $300 \mathrm{ng}$ BOMBESIN (ICV) ON BODY TEMPERATURE AND ON OPEN FIELD ACTIVITY OF VARIOUS TIME INTERVALS

\begin{tabular}{ccccc}
\hline & & $\begin{array}{c}\text { Mean body } \\
\text { temperature } \\
\left( \pm \text { SEM) }{ }^{\circ} \mathrm{C}\right.\end{array}$ & $\begin{array}{c}\text { Mean ambulation ( } \pm \text { SEM) } \\
\text { (crossings in open } \\
\text { field/3 min) }\end{array}$ & $\begin{array}{c}\text { Mean } \\
\text { rearing } \\
\text { frequency } \\
( \pm \text { SEM)/3 min }\end{array}$ \\
\hline Placebo & $(14)$ & $37.0 \pm 0.1$ & $110 \pm 6$ & $9.9 \pm 1.2$ \\
$10^{\prime}$ & $(12)$ & $37.0 \pm 0.1$ & $106 \pm 8$ & $7.8 \pm 1.4$ \\
$20^{\prime}$ & $(12)$ & $36.5 \pm 0.2^{*}$ & $73 \pm 6^{\dagger}$ & $4.5 \pm 0.9^{\dagger}$ \\
$30^{\prime}$ & $(13)$ & $36.4 \pm 0.3^{\dagger}$ & $70 \pm 8^{\dagger}$ & $5.9 \pm 0.9^{*}$ \\
$40^{\prime}$ & $(18)$ & $36.2 \pm 0.3^{\dagger}$ & $88 \pm 5^{\dagger}$ & $6.5 \pm 0.7^{*}$ \\
$50^{\prime}$ & $(11)$ & $36.1 \pm 0.3^{\dagger}$ & $76 \pm 5^{\dagger}$ & $5.0 \pm 1.0^{\dagger}$ \\
$60^{\prime}$ & $(17)$ & $36.6 \pm 0.3$ & $71 \pm 4^{\dagger}$ & $5.0 \pm 1.1^{\dagger}$ \\
$80^{\prime}$ & $(11)$ & $36.9 \pm 0.4$ & $73 \pm 7^{\dagger}$ & $4.8 \pm 0.8^{\dagger}$ \\
$10^{\prime}$ & $(8)$ & $37.2 \pm 0.2$ & $76 \pm 8^{\dagger}$ & $4.9 \pm 1.0^{\dagger}$ \\
\hline
\end{tabular}

( ) Number of animals/group.

$* p<0.05$ (vs. placebo, Dunnet's test).

$t_{p}<0.01$ (vs. placebo, Dunnet's test).

14, 19] that ICV administration of neurotensin induces hypothermia in rats and reduction of locomotor activity. They also confirm the finding that the hypothermic action of the peptide appears at lower doses than the effect on locomotor activity. However, the present findings refute the idea that the suppressive effect of neurotensin on locomotor activity can sufficiently be explained by its hypothermic action. In fact we believe that the two effects studied in the present experiments are not causally related. Several reasons support our opinion in this respect: (1) not all rats exhibiting hypothermia show reduced locomotor activity, (2) maximum hypothermia was observed at $43 \mathrm{~min}$, whereas maximal reduction of locomotor activity was calculated to occur at $32 \mathrm{~min}$, (3) a dose of $1 \mu \mathrm{g}$ neurotensin induces hypothermia but does not reduce locomotor activity significantly, and (4) only in a few cases a significant correlation was found (one-tailed test) between hypothermia and reduced locomotor activity.

Thus our findings do not support a causal relationship between the hypothermic effect of neurotensin and its effect on locomotion. Instead we suggest that these two effects of neurotensin are two different and independent responses, as was also shown for hypothermia and catalepsy [20], for hypothermia and antinociception $[11,14]$. Our results also support the view of a dichotomous action between neurotensin and some of its analogues on locomotor activity, which is not found for the hypothermic effect [10].

Concerning the effects of bombesin on locomotor activity it appears that two timepoints can be calculated at which a peak effect occurs. This may indicate that for the influence of bombesin on locomotor activity (ambulation and rearing) different mechanisms of action are involved or that possible metabolites may also affect locomotion. With respect to the hypothermic effect of bombesin the maximum effect apepars at $47 \mathrm{~min}$, exactly in between the two timepoints at which the peak effects of bombesin on locomotor activity occur (see Fig. 2). Although a weak but significant ( $p=0.5$, one-tailed) correlation was found between the effect of this neuropeptide on locomotion $(\Delta \mathrm{amb}$.) and on body temperature $(\Delta$ temp.) (see Table 5), this does not necessarily point to a causal relationship. The findings that two peaks are found in the time course for the effect of bombesin on locomotor activity and only one for the hypothermic action does not exclude such a causal relationship but makes it not likely. In addition some animals show hypothermia but no suppressed locomotion, whereas others display reduced locomotor activity but no hypothermia following ICV administration of bombesin. In addition the results of the dose-response re- 


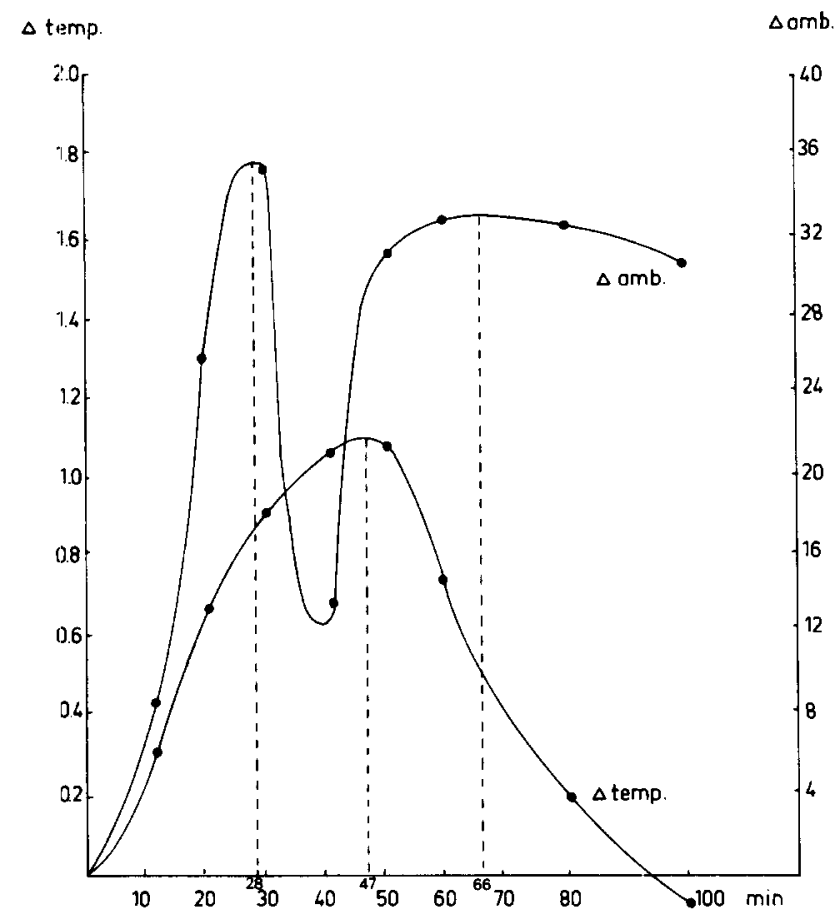

FIG. 2. Time curves of the effect of bombesin ( $300 \mathrm{ng}$, ICV) on body temperature ( $\Delta$ temp.) and on ambulation ( $\Delta$ amb.) in an open field.

laitonship study reveal that higher doses of bombesin are needed for the effect on ambulation and rearing than for the effect on body temperature. Thus, for similar reasons as put forward for neurotensin a causal relationship between the effects of bombesin on body temperature and on locomotor activity is not likely.

The finding that bombesin reduces locomotor activity seems in contradiction with the observation by Pert $e t$ al. [18]. However the way they measured locomotion (horizontal movement) is different from the ambulation and rearing we observed in the open field. In addition differences in other experimental conditions may play a role as well and may account for the discrepancy between their findings and the ones described in the present study. That grooming was not increased after bombesin administration seems in contradiction with the reports of Katz [12] and of Gmerek and Cowan [9]. However the open field is not the most appropriate way to study grooming. Preliminary experiments performed by us recently clearly indicate that bombesin induces excessive grooming behavior, when appropriate observation boxes for this type of stereotype behavior are used.

Comparing the effect of neurotensin and of bombesin on body temperature and locomotor activity in an open field it appears that the time curve of both peptides on body temperature is rather similar albeit that higher doses of neurotensin as compared to bombesin are needed for a similar fall in body temperature. Concerning the reduction of

TABLE 5

SPEARMAN RANK CORRELATION COEFFICIENT FOR $\Delta$ AMBULATION AND $\triangle$ TEMPERATURE AFTER ICV ADMINISTRATION OF 300 ng BOMBESIN

$\Delta$ temperature at $45 \mathrm{~min}$ $\Delta$ ambulation at $30 \mathrm{~min}$ $0.643^{*}(8)$

$\Delta$ Temperature was established at $45 \mathrm{~min}$, whereas $\Delta$ ambulation was determined at $30 \mathrm{~min}$ (first peak, see Fig. 2) or at $60 \mathrm{~min}$ (second peak, see Fig. 2).

${ }^{*} p=0.05$ (one-tailed test).

( ) Number of animals/group.

TABLE 6

SPEARMAN RANK CORRELATION COEFFICIENT FOR $\triangle$ TEMPERATURE (45 MIN) AND $\triangle$ AMBULATION (30 MIN) AFTER ADMINISTRATION OF GRADED DOSES OF BOMBESIN

\begin{tabular}{ccc}
\hline $\begin{array}{l}\text { Doses bombesin } \\
\text { (ng, ICV) }\end{array}$ & $\begin{array}{l}\text { Number } \\
\text { of rats }\end{array}$ & $\begin{array}{c}\text { Correlation } \\
\text { coefficient }\end{array}$ \\
\hline 30 & 9 & 0.167 \\
100 & 9 & 0.454 \\
300 & 7 & 0.700 \\
\hline
\end{tabular}

locomotor activity in an open field the time curves of neurotensin and of bombesin are quite different with respect to the shape of the curve, as well as the duration and the strength of the effect. This may suggest that different mechanisms underly the suppressive effects of neurotensin and of bombesin on exploratory behavior (ambulation) in an open field. This holds in particular for the mechanism resulting in the second part of the $\Delta$ amb. curve of bombesin (see Fig. 2).

The observation that the control groups from the neurotensin and bombesin studies seem to have different ambulation scores may be explained by the fact that these respective experiments have been performed with an interval of approximately half a year.

In conclusion it can be stated that, although occasionally a correlation exists between the effects on ambulation and body temperature, a causal relationship between the hypothermic effect of the two neuropeptides studied, and their suppressive action on locomotion is not likely. In addition it is suggested that the mechanisms by which neurotensin and bombesin influence locomotor activity are of a different nature.

\section{ACKNOWLEDGEMENTS}

The authors are very grateful to Dr. Ch. B. Nemeroff (Chapel Hill, NC) who supplied them with neurotensin and to Dr. J. Rivier (La Jolla, CA) who supplied them with bombesin.

\section{REFERENCES}

1. Avery, D. D., M. F. Hawkins and B. A. Wunder. The effects of bombesin into the cerebral ventricles on behavioral thermoregulation. Neuropharmacology 20: 23-27, 1981.
2. Bissette, G., Ch. B. Nemeroff, P. T. Loosen, A. J. Prange and M. A. Lipton. Hypothermia and intolerance to cold induced by intracisternal administration of the hypothalamic peptide neurotensin. Nature 262: 607-609, 1976. 
3. Bissette, G., P. Manberg, Ch. B. Nemeroff and A. J. Prange Jr. Neurotensin, a biologically active peptide. Life Sci 23: 2173$2182,1978$.

4. Brown, M., J. Rivier and W. Vale. Bombesin: Potent effects on thermoregulation in the rat. Science 196: 998-1000, 1977.

5. Brown, M., J. Rivier and W. Vale. Actions of bombesin, thyrotropin releasing factor, prostaglandin $\mathrm{E}_{2}$ and naloxone on thermoregulation in the rat. Life Sci 20: 1681-1688, 1977.

6. Brown, M. R., J. Rivier and W. W. Vale. Bombesin affects the central nervous system to produce hyperglycemia in rats. Life Sci 21: 1729-1734, 1977.

7. Clineschmidt, B. C., J. C. McGuffin and P. B. Bunting. Neurotensin: Antinocisponsive action in rodents. Eur $J$ Pharmacol 54: 129-139, 1979.

8. Gibbs, J. and D. J. Fauser. Bombesin suppresses feeding in rats. Nature 282: 208-210, 1979.

9. Gmerek, D. E. and A. Cowan. Tolerance and cross-tolerance studies on the grooming and shaking effects of ACTH-(1-24), bombesin and RX 336-M. Fed Proc 223: 274, 1981.

10. Jolicoeur, F. B., A. Barbeau, F. Rioux, R. Quirion and S. St. Pierre. Differential neurobehavioral effects of neurotensin and structural analogues. Peptides 2: 171-175, 1981.

11. Kalivas, P., L. Jennes, Ch. B. Nemeroff and A. J. Prange, Jr. Neurotensin: topographical distribution of brain sites involved in hypothermia and antinociception. J Comp Neurol 210: 225$238,1982$.

12. Katz, R. Grooming elicited by intracerebroventricular bombesin and eledoisin in the mouse. Neuropharmacology 19: 143$146,1980$.

13. Kulkosky, P. J., J. Gibbs and G. P. Smith. Behavioral effects of bombesin administration in rats. Physiol Behav 28: 505-512, 1982.
14. Martin, G. E., T. Naruse and N. L. Papp. Antinociceptive and hyperthermic actions of neurotensin administered centrally in the rat. Neuropeptides 1: 447-454, 1981.

15. Nemeroff, Ch. B. Neurotensin: Perchance an endogenous neuroleptic? Biol Psychiatry 15: 283-302, 1980.

16. Nemeroff, Ch. B., A. J. Osbahr, III, P. J. Manberg, G. N. Ervin and A. J. Prange, Jr. Alterations in nociception and body temperature after intracisternal administration of neurotensin, $\beta$-endorphin, other endogenous peptides and morphine. Proc Natl Acad Sci USA 76: 5368-5371, 1979.

17. Nemeroff, Ch. B., D. Luttinger and A. J. Prange, Jr. Neurotensin and bombesin. In: Handbook of Psychopharmacology, vol 16, Neuropeptides, edited by L. L. Iversen, S. D. Iversen and S. H. Snijder. New York: Plenum Press, 1983, pp. 363-466.

18. Pert, A., T. W. Moody, C. B. Pert, L. A. Dewald and J. Rivier. Bombesin: Receptor distribution in brain and effects on nociception and locomotor activity. Brain Res 193: 209-220, 1980.

19. Siegel, S. Nonparametric Statistics: For the Behavioral Sciences. New York: McGraw-Hill, 1956.

20. Snijders, R., N. R. Kramarcy, R. W. Hurd, C. B. Nemeroff and A. J. Dunn. Neurotensin induces catalepsy in mice. Neuropharmacology 21: 465-468, 1982.

21. Weijnen, J. A. W. M. and J. L. Slangen. Effects of ACTHanalogues on extinction of conditioned behavior. Prog Brain Res 32: 221-235, 1970.

22. Wimersma Greidanus, Tj. B. van, M. C. G. van Praag, R. Kalmann, G. J. E. Rinkel, G. Croiset, E. C. Hoeke, M. A. H. van Egmond and M. Fekete. Behavioral effects of neurotensin. Ann NY Acad Sci 400: 319-329, 1982. 